\section{Danske digtere i Italien}

\section{af forfatter Soren Sorensen}

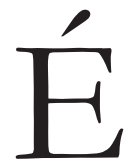

$\mathrm{n}$ ting er inspirationen fra rejsen til det skonne land - il bel paese som Petrarca kaldte det. Noget andet er en fornyet interesse for klassikerne. Bogmarkedet er optaget af dem. Virgil og Ovid er kommet i nye oversættelser, og som romere er de en slags italienere. Dante og Petrarca er kommet på danske vers, Dante igen for fjerde gang.

For Petrarca sker det i grunden for første gang; før 2005 har der stort set kun eksisteret de ti i og for sig klassiske oversættelser som P.L. Møller udgav i 1847 og Kai Friis Møller genudgav i 1944. ${ }^{1}$ I 2011 udkom den komplette Canzoniere på dansk. Man har hørt rygter om at Boccaccio er på vej i en ny oversættelse; hans noveller fra Decameron dog, ikke hans digte. ${ }^{2}$ I tidsskrifter har også Angelo Poliziano og Torquato Tasso vist deres poetiske navnetræk. Michelangelo, maleren, var også digter. Som Michelagniolo Buonarotti har vi kendt ham siden 1912. Da viste revymanden Johannes Dam sine evner som lyrikoversætter. Fem år senere gav han endda sine danske læsere Dantes Vita nuova Nyt Liv, året efter et endnu større udvalg af Lyrisk Digtning fra Dantes hånd og ånd.

Et århundrede senere står Dante igen stærkt, og ikke kun blandt digtere. Forskere og kommentatorer har ikke ligget på den lade side. Jan Lindhardt har i én bog drøftet Dante som politisk tænker, Jakob Balling $\mathrm{i}$ en anden $\mathrm{i}$ hans egenskab af teologisk autoritet, og fra Nordisk Dante-netværk er der kommet flere bind om flere sider af værket. Hans overvejelser om sprog og poesi er blevet gjort tilgængelig for danske læsere med Hanne Roers og Christian Høgels Dante om poesi og sprog 2008. Tilmed gav Jørgen Sonne i 2007 et lille udvalg af hans lyriske værker, sonetter og en af sestinerne fra de stenede digte, Rime petrose i Europaisk lyrik.

Selveste Inger Christensen skrev i 1969 til Danmarks Radio et kort essay om grunde til at læse Dante - og hun tænkte alene på Den guddommelige Komedie:

Der er $i$ bvert fald tre grunde til at lase Dante:

for det forste er han ulaselig, for det andet er hans ideologi fuldstandig irrelevant,

og for det tredje er på den ene side Dante på den anden side Helvede,

Skarsild og til dels også Paradis narmest synonyme. $^{3}$

Heri hævder Inger Christensen bl.a. at Dante har bestemt resten af litteraturens liv på samme måde som de første barndomsoplevelser hos den enkelte bestemmer resten af ens liv, selv om man netop ikke iflg. Inger Christensen kan få dem til at betyde noget, ikke kan bruge dem til noget.

Mere end noget andet demonstrerer Inger Christensen netop at hans hovedværk netop er et hovedværk, også o. 1970 . 
Det er dog tvivlsomt om man kan finde spor af Dantelæsning i hendes digte.

I hvert fald står hun ikke alene med sin optagethed af komedien. I disse år er mange digtere optaget af Divina Commedia. Ib Michael har bygget en digtsamling fra 2000 op som en parallel til Komedien, tilmed brugt Dantes førerfigur, men erstattet romeren Virgil med svenskeren Gunnar Ekelöf, en stor inspirator for vores generation. Rosa Mundi kaldte
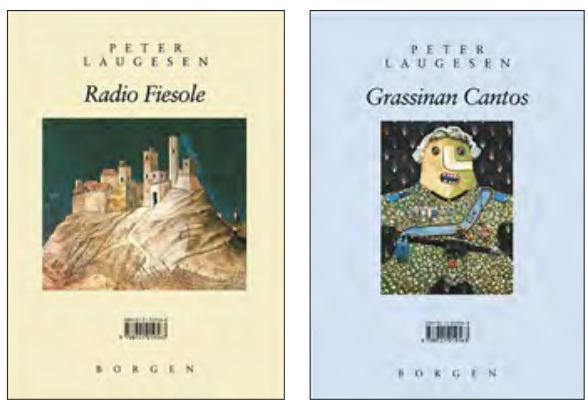

han den. To år senere udsender Peter Laugesen en dobbeltbog som fra den ene side hedder Radio Fiesole, fra den anden Grassinan Cantos.

Det er helt indlysende at han som andre nutidige danske lyrikere ${ }^{4}$ er mere engelsk-amerikansk end italiensk påvirket. Modernismen har flere fædre, den amerikanske digter Ezra Pound (1885-1972) er én af dem, en enestående stilskaber og læremester for 1900-tallets europæisk-amerikanske lyrik. En meget lærd digter med et dybtgående kendskab til klassisk litteratur, ikke mindst italiensk. For de danske Italiensrejsende digtere har det en vis betydning at Pound boede i Italien fra 1924 til 1945 og igen fra 1958 til sin død. Hans værker har titler som $A$ lume spento ['Ved slukket lys"], The Pisan Cantos [Pisasangene].

Ezra Pound er indiskutabelt Laugesens forbillede helt ud i titlerne, men ikke desto mindre figurerer Dante side om side med Pound i tilegnelsen. Allerede det fjerde digt citerer en beskrivelse af Den Guddommelige Komedie, mens det sjette låner sin titel fra Dante og hedder Vita Nuova; digtet beskriver Laugesens betagelse af hans elskede i en variant af Dantes møder med Beatrice netop i Vita Nuova. Et andet hedder De Vulgari Eloquato ['Udtrykt om folkets sprog"] - og det varierer Dantes afhandling om veltalenhed på folkesproget: De vulgari eloquentia. ${ }^{5}$ I et af digtene siger Peter Laugesen det som det er:

\section{Der er ikke noget historisk ved Dante.}

Dante er nu og allevegne her.

Det er Dante altså også i Martin Larsens Det stof alting er gjort af $2001 \mathrm{og}$ i Jan Thielkes digtsamling Anden er over os fra 2005. Denne samling er delt i tre bøger: Forste bog (Helvede) hvor forste afsnit hedder Vi er velkomne, Anden bog (Skecrsild) hvor Vi vil ankomme og Tredje bog altså (Paradis) med Vi er her og alt er lykke. Interessant nok er Martin Larsen tilsyneladende mere optaget af Vita Nuova og tager afsæt i dette værk til en afveksling.

Mindre ekstatisk end hos Thielke går det for sig i Søren Sørensens Festival fra Troldspejl 2008, den indtil videre seneste af de Danterefererende digtsamlinger.

Andre italienske lyrikere dukker op her og der, 1700-tallets tragediedigter Vittorio Alfieri (1749-1803) i Schandorphs store roman Poet og Junker hvori 


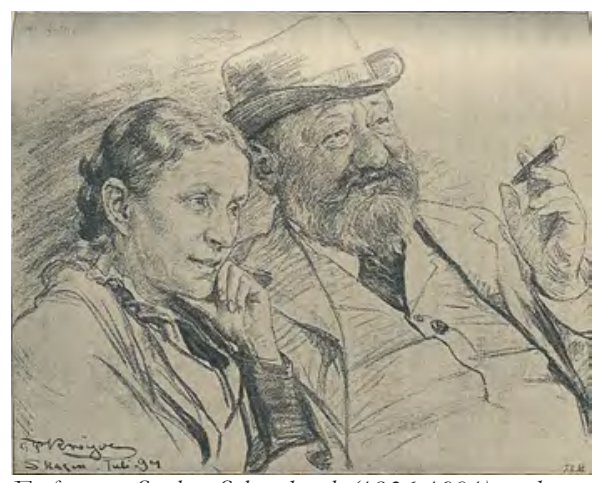

Forfatteren Sophus Schandorph (1836-1901) med bustru, 1894, af P.S. Kroyer.

en af Alfieris sonetter, Italien, Du, hvis Storheds Glans er slukket, danner et af omdrejningspunkter i romanens handling. Nobelpristageren Carlo Carducci (1835-1907) møder man hos Johannes Jørgensen og Sophus Claussen. Hos Niels Møller og Søren Sørensen kan man møde humanisten Angelo Poliziano (1454-1494) fra Firenze, en af de tidlige Petrarca-elever i europæisk litteratur. Jørgen Sonnes Europaisk lyrik fra 2007 giver en række eksempler fra den italienske litteraturhistorie: Frans af Assisi, Dante Alighieri, humoristen Cecco Angiolieri, Boccaccio, Petrarca, Ludovico Ariosto, Torquato Tasso og Michelangelo Buonarotti og andre. Derudover har Jørgen Sonne oversat en stribe italienske lyrikere fra 1800- og 1900-tallet: Eugenio Montale (1896-1981) Digte 1976, romantikeren Ugo Foscolo (1778-1827), Giuseppe Ungaretti (1888-1970) og Salvatore Quasimodo (1901-1968) bl.a. Ungaretti er ligeledes oversat af Annemette Kure Andersen i 1999.

Det ses af lyrikernes værker at de har stiftet bekendtskab med deres italienske forbilleder og har lært af dem. Ofte kom- mer indtryk fra Italien til udtryk i brugen af italienske versformer, man finder terziner hos Oehlenschläger og Johannes Jørgensen (efter Dante), sonetter hos Staffeldt, Ingemann, Claussen, Stuckenberg, Klaus Høeck og Søren Sørensen (efter Petrarca). Nævne dem gør de ofte; hos Oehlenschläger kan man se inspirationen så at sige samlet:

\section{Jeg horte Leonardos, Pergoleses Toner} skicelve,

Hvor magtig sig San Pietros Buer hvalve,

Og Buonarotis Hvalving brast,

Og Himlen viste mig sit Øiekast:

Jeg Engle saae $i$ hvide Flaggerklader

Til Jesu, til Marias Hader

At have Salighedens Rost;

Den boiede mit Kna, den svulmede mit

Bryst.

Jeg horte Jordens Jammer,

Et Miserere qualt af Helvedflammer;

Da valdigt $i$ mit Ore klang,

Hvad Dante ved sit store Orgel sang,

I digtet Tilbageblik paa Rom som indgår i dette udvalg, får vi repeteret Petrarca, Horats hele tre gange, og Virgil, siden Ariost, Rafael, (Michel)Angelo og Tasso. Emil Frederiksen har i sin bog om Dante fra 1965 sporet læsningen af Den Guddommelige Komedie hos Oehlenschläger, Grundtvig, H.C. Andersen. Martensen, Kierkegaard og frem til Karen Blixen, Jørgen Gustava Brandt, Villy Sørensen og Poul Ørum. Stærkest forekommer han, synes det, hos Johannes Jørgensen. Gennem arbejdet med store biografier om de katolske helgener fra 1200- og 1300-tallet havde han erhvervet sig særlige forudsætninger for 
at forstå hvordan man tænkte på Dantes tid.

Mere overraskende er det måske at naturalisterne også var fortrolige med La Divina Commedia. Korrespondancen mellem J.P. Jacobsen og Edvard og Georg Brandes viser at de alle tre ikke blot kendte værket, men også citerede det på italiensk.

I Dantestemninger I-IV fra 1913 lægger just Johannes Jørgensen sine ord i munden på Dante og parafraserer hovedværkerne, Komedien i I og IV, Vita nuova i II og III. En Skov saa dunkel osv. henter han direkte fra Komediens I. sang:

På midten af vor bane gennem livet jeg fandt mig i skovs balgmorke sale. ${ }^{6}$

Andre steder er der skjulte citater eller henvisninger til Dantes værker, og Johannes Jørgensen skrev siden både essays og prosadigte om ham; ved markeringen i 1921 af 600-året for Dantes død var Jørgensen til stede i Ravenna og reciterede sin Hilsen til Dante ved graven. På mange måder så Svendborgdigteren sin egen skæbne i digteren fra Firenze, begge var eller følte sig landsforviste, begge havde stærke oplevelser af livet som en vandring i en skovs balgmorke sale,

en Skov, der groer i evige Natters Morke og forer ind til Staden, fuld af Jammer.

- Og netop dette vers i Jørgensens Dantestemning I er et direkte citat fra Molbechs oversættelse af Helvede 3. Sang.

Vita Nuova optog ham meget i årene mellem Dantestemninger og Hilsen til Dante. Det var i den periode han opholdt



Lucifer kvaler de tre forradere Judas, Brutus og Cassius. Dante, Commedia. 14. årh., Italien. Codex Altonensis, folio 48r. Ex Bibliotheca Gymnasii Altonani (Hamburg).

sig i Siena og skrev på bogen om Den hellige Katarina; den kreds af litterater han da færdedes i, var som italienske nationalister stærkt optaget af Dante og citerede og kommenterede ham tit og ofte.

Også Jørgensens generationsfæller, Sophus Claussen og Viggo Stuckenberg, kom ind på den store Alighieri, Claussen ordrigt og nærgående, Stuckenberg overlegent og med det store overblik, som når han i sonetten om Florenz' kampe

... reddes for den syge Fantasi, der skaber dem paany af Arnos Dampe.

Formentlig er det et ekko af Brandes. Hans holdning til Dante var den at hans Helvede er produkt af en Boddels Fantasi. Men læse ham gjorde de, som også Oehlenschlæger havde gjort det i 1800-tallets første årti; Sophus Michaëlis 
skriver i digtet Jasminen:

I den lyse Nat en Blomst der skinner

- $i$ min aabne Dante jeg den finder.

Sophus Claussen husker i Siena ${ }^{8}$ hvad Dante har skrevet om en adelig dame dér fra byen, optaget som han er af spillet mellem ham og

\section{Herskabets Damer, der vandrer langsomt \\ op og ned}

under mine opmarksomme Vinduer,

ja, han spiller på samtalen i 13. sang af Skarsilden mellem Dante og senesiske Sapia, som trods sit navn ikke var vis, og citerer et vers ordret og i egen oversættelse. $^{9}$

Tre menneskealdre senere tog Peter Laugesen tråden op og konstaterede: Der er ikeke noget historisk ved Dante, og det er formentlig rædslerne i den forpinte by med overskriften $L A D A L T H A B$ FARE, I DER HER GAR IND ${ }^{10}$ han har tænkt på med sine og sin generations erfaringer fra Bosnien og Vietnam og minderne om Auschwitz og Babi Jar.



en der skriver dette, har $\mathrm{i}$ artikler dokumenteret Petrarcalæsningen hos nordiske forfattere. Staffeldt, Ingemann, Winther og Claussen var hvad man vel må kalde petrarkister, ${ }^{11}$ i europæisk lyrik en hædersbetegnelse der begyndte som et foragteligt nedsættende udtryk om smagløse epigoner, men den udvikling har mange betegnelser i kunstarternes historie gennemgået, impressionisme, fauvisme, jazz ...

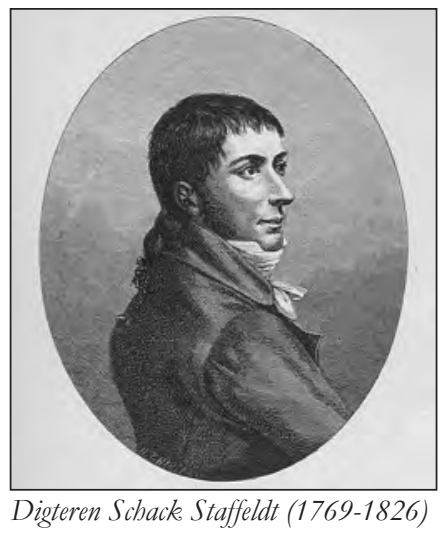

I indhold og tankegods så vel som i det formelle var den tyske romantik den direkte forudsætning for den dansknorske. De tyske romantiske digtere var optaget af Petrarca og skrev digte i hans stil, d.v.s. sonetter. Man talte om deres Sonettenwut, sonetraseri. Det fik ikke rigtigt fat i Oehlenschläger, til gengxld havde sygdommen greb om Schack Staffeldt. Hans eneste konkurrent i romantisk digtning var Adam Oehlenschläger, og denne havde måttet nøjes med en 16 timers samtale med den norske filosof Henrik Steffens, der gav gæsteforelæsninger i København. Schack Staffeldt havde studeret længe og grundigt i Göttingen og siden tilbragt næsten tre år i Italien. I hvert fald er Schack Staffeldt om nogen petrarkisten i dansk litteratur.

Antageligt var han blevet ledt på sporet ved at læse Schillers Lauradigte. ${ }^{12} \mathrm{Un}$ der opholdet i Göttingen havde han læst Petrarca, og allerede da var han begyndt at skrive digte der viser spor af den inspiration han hentede fra denne læsning. Den udgjorde imidlertid ikke hele Staffeldts Petrarcalæsning; mange udgaver 
rummer nemlig foruden de 366 digte deri også Trionfi, Triumferne. De udgør en række digte - på samme versemål som Dantes, terzinen - og handler om kærlighedens, kyskhedens, dødens, berømmelsens, tidens og evighedens eller det guddommeliges triumf. Som motto satte Staffeldt to vers herfra, de sidste og endegyldige i Trionfo dell' Eternità:

\section{Se fu beato chi la vide in terra, or che fia dunque a rivederla in cielo? ${ }^{13}$}

Dette udsagn har haft særlig betydning for ham, han brugte det igen i et af sine danske digte, Erindringer tre år senere.

Under sit ophold i Italien 1797-1800 fik Staffeldt opfrisket sit forhold til Petrarca. Måske var det i de år han tillagde sig vanen med at have Canzoniere som rejselekture, og det er formentlig snarest påvirkningerne fra læsningerne i den der gjorde ham til den store sonetdigter $\mathrm{i}$ dansk litteratur. Det førte ham også til i en sonet at diskutere formen selv, og det kan ikke mange gennemføre uden at Petrarca bliver blandet ind i redegørelsen, og da heller ikke Staffeldt:

\section{For Sonnettets Genius kun laret Gad Petrarchas spade Veemodsquad, Han paa Liljekalkens Bredde sad, Kialent klukkende i Aftenskicret.}

Petrarcas navn dukker op igen og igen hos Staffeldt, og ikke mindst i hans erotiske digte. Et af dem hedder Elskovs Rige, og heri tegnede han de karakteristiske træk ved kærligheden i et universelt ordmaleri:
O Elskov! du hvis Tryllevalde

Tilbedes af den hele Jord,

Om Daarskab, Viisdom, Ungdom, Ælde

Du dine Straalekieder snoer. ${ }^{14}$

I vers efter vers afbildes kærlighedens væsen som det frieste af alt, ubundet af alle love, det der får enhver jordisk magt til at visne bort i dets glød: kalifatets krone (v. 25), cæsarernes trone (v. 27); men på et felt hvor så mange digtere lige fra de gamle grækere som Sapfo og Alkaios over Salomon og de store romere til moderne europæere, alle dybt erfarne i erotikkens kunstformer, har Petrarca som den eneste af dem alle fundet omtale:

Der sukeer du, toscanske Svane,

Ei dybt ved din Madonnas Fod, Hun favner dig, skiondt uden Ane

Og dode Sekler $i$ dit Blod. ${ }^{15}$

Og faktisk optræder Canzonieren som et håndgribeligt fænomen i Staffeldts digte, en fysisk bog han skal have med på rejse.

Hans petrarkisme var smittende. Den indgik i den indflydelse han øvede på B.S. Ingemann, og just denne fortsatte hvor Oehlenschläger havde sluppet: med at oversætte Petrarca. Han viste sig i Digte 1817 som en glimrende fortolker af sonetto CLIX:

I bvilken Himmel, bvilkeen boi Idee

Fandt du, Natur! et Mynster for hint

Billed,

Hint skejonne Aasyn, bvori du har villet Afbilde her hvad hist kun Engle see. 
Hvor var den Kildens Moe, den Skovens

Fee,

Hvis fagre Guldhaar saa for Vinden

spilled,

Hvis rene Sjal var saa Guds eget Billed?

- Dog i den Himmel jeg min - Dod maa

see.

\section{Forgjaves efter Guddomsskjonhed iler}

Den digter, som ei hendes Oine saae,

Hvor sodt de rulle imod Himlens Blaa.

Han veed ei, Balsom paa Dodspilen hviler,

Som ikke veed, hvor sodt bun sukke maa,

Hvor sodt bun taler, og hvor sodt bun

smiler. ${ }^{16}$

20 år senere påtog P.L. Møller sig opgaven. Han nåede at gendigte hele ti digte fra Canzoniere, fire sonetter, to ballader og fire sestiner, de blev optaget i hans Ballader og Sange 1847.

Men digterne læste Petrarca, og de henviste til hans værker når lejlighed gaves. Den elskede burde hedde Laura, det mente f.eks. Poul Martin Møller også i tre sonetter, for det hedder den dame Petrarca digter om. Navnet Laura blev opfattet som et kendetegn på en kvinde digteren elsker, men ikke kan få. Sådan beskrives hun jo af Petrarca i Canzoniere.

Steen Steensen Blicher kunne også sin klassiker og gjorde brug deraf. Man tør gå ud fra at Ingemann på sin Italienstur har haft et bind i rejsetasken.

Mon ikke også Simon Meisling på Slagelses lærde skole har kunnet sin Petrarca? En af hans elever kunne ham $\mathrm{i}$ hvert fald, og et sted har H.C. Andersen inspirationen fra. Allerede i Fodreise fra Holmens Kanal til Østpynten af Amager 1829 dukker Petrarcas navn op i det surrealistiske mylder af allusioner. En grundig gennemgang gav H.C. Andersen i Improvisatoren 1835, med så megen bedre begrundelse som den handler om en italiensk ynglings uddannelse til digter.

I Andersens farverige roman findes altså den grundigste drøftelse af Petrarcas digtning uden for faglitteraturen, så ung var romanen i 1835. Improvisatoren, romanens hovedperson, fulgte modestrømningen i Italien og forkastede Petrarca som gammel hofsnog og klerikal til fordel for den Dante de italienske nationalister gjorde til en revolutionær. ${ }^{17}$

Men Improvisatorens forfatter fortsætter også i senere værker med at citere Petrarca, ungdomsårenes stærke indtryk af hans læsning forlod ham aldrig. De dukker op i romanen De to Baronesser 1848, igen fra 1863 i rejsebogen I Spanien:

...to unge Piger [...]; deres Mund sagde ved et eneste Smiil Mere, end nogen Digter

kan sige $i$ et langt Digt, Byron og Petrarca tilgive mig!

De færdedes og trivedes i Italien, de digtere der var unge sammen med Andersen; de havde de samme inspirerende forgængere og samtidige som han: Goethe, Staffeldt, Byron og Heine, og ligesom Goethe, Staffeldt og Byron modtog de stærke indtryk af alt hvad de så under rejserne i Italien. Og læste, for selvfølgelig læste de Petrarca når de nu havde lejlighed til det.

Det gjaldt Christian Winther, og ikke den evindelige Alvilde Müffelmann - på trods af forholdets påfaldende lighed med Petrarcas til Laura. Derimod mødte 
han Een, og hende måtte han skrive så mange vers at de blev en samling med den titel: Til Een. Som motto for den måtte han sætte de bittersøde ord fra forbilledets vist nok mest berømte og eftergjorte sonet, Canzonierens nr. XXXV:

"Ma pur si aspre vie, ne si selvaggie Cercar non so, ch'amor non venga sempre Ragionando con meco, ed io con lui." 18

For Oluf Friis der i 1927 skrev indledningen til Winthers Poetiske Skrifter var afhængigheden af Petrarca aldeles indlysende, kun at sammenligne med Homers betydning for Oehlenschläger.

Winther kunne endda dementere Byrons kyniske betragtninger, i Drachmanns fordanskning således lydende:

Romaner gi'er vor Sorg $i$ hel Figur men kun i Buste Ægtestandens Glader. Hvad angaar os de omme Mand og Fru'r? de Kys kan frit passere alle Steder; sat Laura var Petrarca's Kone blevet, hvem skulde saa hans Bind Sonetter skrevet? ${ }^{19}$

Efter at være blevet gift med denne Eene øgede Christian Winther antallet af netop sonetter, men det var han ikke ene om i årene efter 1850. Det er karakteristisk i dele af nordisk lyrik i den periode.

Sophus Schandorphs roman om Alfieri - Poet og Junker - handler især om hans kærlighed til den engelske dronning i eksil, grevinden af Albany. Her er Petrarca og hans elskede Laura den helt selvfølgelige reference, for de elskende selv som for deres venner, dette så me-

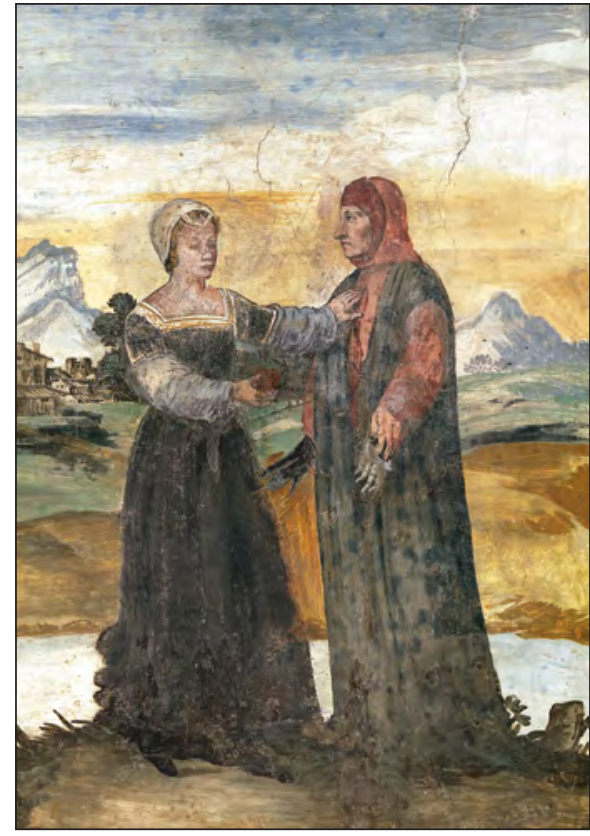

Laura og Petrarca.

get mere som Alfieri egentlig er fransktalende (fra Savoyen) og må tilegne sig italiensk, bl.a. ved at læse Dante, Boccaccio og Petrarca.

Men karakteristikkerne af Petrarca røber tillige at Schandorph selv absolut ikke var ubekendt med mesteren. Således lader han sin hovedperson udtale:

Dante fik ikke nogen Hjord af Efterlignertralle efter sig, som Messer Francesco Petrarca fik. Hans Efternynnere bragte Dantes Basuner og Palestrinas Orgelpiber til Tavshed. ${ }^{20}$

Selv den fordrukne og elendige britiske tronprætendent, grevindens skrækkelige ægtemand, kan citere Canzonierens første digt Voi, ch'ascoltate in rime sparse il suono. $^{21}$ 


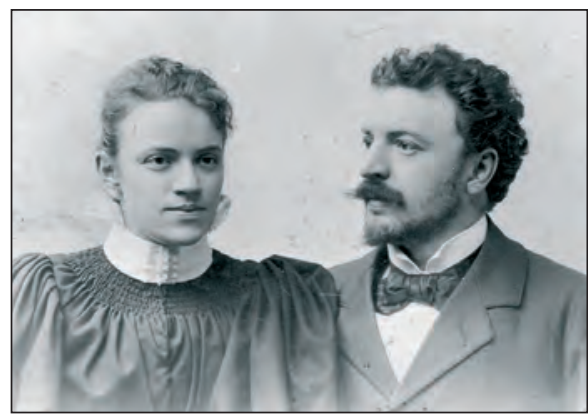

Digteren Sophus Claussen (1865-1931) og bustru.

Sophus Claussen er den af 90'ernes digtere der oftest har henvist til sin erotikerkollega fra 1300-tallet: i rejseromanen Valfart 1896 skildrede han indtrykket af den kvindelige skønhed syd for Alperne: Enhver Italienerinde er som et Udkast til en Madonna, men efter en lidt for nem affære i toget fra Siena måtte han konstatere:

"De er saa pyntelige som Petrarcas Sonetter", sagde jeg dem.',22

"Men de smalter, naar Solen skinnerpaa

Det forhindrede som bekendt ikke Claussen i at blive en af Staffeldts og Winthers tro følgesvende just i sonetformen - den var da ganske vist også kommet på mode igen på den tid. En nærmere undersøgelse af Claussens Petrarcalæsning venter på sin forsker, men i Winthers fodspor satte også han en Petrarcastrofe som motto for en digtsamling: afsnittet Rejsebilleder i Pileflojter 1899 - som han så indleder med 16 sonetter hvori han hylder Aarestrup og
Heine. Det kan diskuteres hvor ironisk mottoet kan være ment, for så vidt både hos ophavsmand og låntager:

Jeg indser vel jeg var til spot for mange, At gud og hver mand lo til alle tider,

Og ofte fik.jeg skam for gammel skade. ${ }^{23}$

Muligvis var det også Aarestrup og med ham Oehlenschläger der inspirerede til Claussens heksameterdigte, værker der må regnes blandt de bedste, der er skrevet på danske, ${ }^{24}$ man kan dog nok ikke uden videre afvise Petrarca som inspiration i heksameterdigtningen fra Goethe og frem til Claussen.

Efter ham bliver sporene næsten udviskede. Grete Heltberg citerer i en sonet Byrons bon mot om

\section{Hvis Laura og Petrarca havde levet}

I hellig agtestand, $i$ stille lykke

Som hverdagslivets fanger, tro og trygge,

Hvem havde da hans elskoussange skere-

$$
\text { vet? } ?^{25}
$$

Først med Peter Laugesen i 2002, Søren Sørensen og Jørgen Sonne med oversættelser henholdsvis 2005 og 2006, efterfulgt 2011 af den komplette fordanskning, dukker hans op. Ikke overraskende er det hos hans oversætter at hans navn og værk optræder i digte: $\mathrm{i}$ Sørensens Troldspejl og andre digte 2008, og igen i EllekrogsElegier 2011.

Det samme gælder i forskningen, som det også er tilfældet med Dante også i forskningen. 
Noter

1 Se www.ordret.dk/Specialer/Petrarca.

2 En enkelt sonet (urimet) findes på dansk i Jørgen Sonnes Europaisk. byrik 2007

3 Trykt i essaysamlingen Del af labyrinten Kbh 1982.

4 Som Peter Poulsen i et digt i Cikaderne synger til Uffe Harder.

5 Jf. Roer og Høgels Dante om poesi og Sprog. Odense 2008. Originalens titel: De eloquentia vulgare.

6 Chr. K.F. Molbechs oversættelse 1855-62.

7 Citeret efter Emil Frederiksen: Dante Kbh. 1965 p.127.

8 I digtet Endnu Siena fra Valfart Kbh 1896.

9 Nemlig Purgatoriet XIII, vv. 106-128.

10 Ole Meyers fordanskning år 2000.

11 Petrarca-spor i nordisk litteratur i tidsskriftet Spring nr. 25 p. 47 Kbh. 2008.

12 Det mente Hakon Stangerup i Schack Staffeldt Kbh 1940 p. 62.

13 Hvis den var salig som så hende på jorden/ hvad sker der så når han genser hende $\mathrm{i}$ himlen?

14 Samme p. 210.

15 Samme p.211 vv 45-48.

16 Jf. Sonetto CLIX In qual parte del ciel Canzoniere 2005 p. 182.

17 Se Amedeo Quondam: Petrarca, l'italiano dimenticato. Milano 2004, og Ivan Z. Sørensen:Små historier fra Firenze 2010.
18 Stavemåden i henhold til Winthers i Samlede Digte København 1905 Bind 3. Der er flere fordanskninger at vælge imellem: P.A. Rosenbergs fra $1910 \mathrm{og}$ min fra 2005; ordret hedder det:

Men så uvejsomme veje eller så vildsomme

Ved jeg ikeke at opsage at Amor ikeke kommer der altid

Og rasonnerer med mig, og jeg med ham.

Karligheden kan man ikke rende fra.

19 Byron: Don Juan III Sang VIII str. p. 203 i Udgaven 1882. Grethe Heltberg genoptog i øvr. tanken i 1944 i digtet Spejlet og i lidt elegantere vers.

20 Schandorph foregreb dermed vægtige udsagn i Petrarcaforskningen, bl.a. andre Karl-Heinz Stierle, jf. kommentardelen i Francesco Petrarca: Canzoniere eller Sangenes Bog Anden udvidede Udgave 2011.

21 På dansk: Af jer som i de spredte digte hører (Canzoniere 2011)

22 Sophus Claussen: Samlede Digte IV København 2000 p. 134: The poem Et lost Udkast

23 Sophus Claussen: Samlede Digte I 2000 p. 125, oversættelsen Canzoniere 2005 p. 17.

24 Homeroversattelser og Heksameterdigte - Linjer gennem den danske litteraturs bistorie Odense 1974 p.231 - en gennemgang hvori der karakteristisk nok ikke er én henvisning til Petrarca.

25 Digtet Spejlet fra Evig Ild 1944. 